\title{
The nutritional content of supermarket beverages: a cross-sectional analysis of New Zealand, Australia, Canada and the UK
}

\author{
Lynne Chepulis ${ }^{1, *}$, Gael Mearns ${ }^{2}$, Shaunie Hill ${ }^{3}$, Jason HY Wu ${ }^{4}$, Michelle Crino ${ }^{4}$, \\ Sarah Alderton ${ }^{5}$ and Katharine Jenner ${ }^{5}$ \\ 'Waikato Medical Research Centre, University of Waikato, Hamilton 3216, New Zealand: ${ }^{2}$ School of Clinical \\ Sciences, Auckland University of Technology, Auckland, New Zealand: ${ }^{3}$ Department of Nursing, Toi Ohomai \\ Institute of Technology, Rotorua, New Zealand: ${ }^{4}$ George Institute for Global Health, University of New South Wales, \\ Sydney, NSW, Australia: ${ }^{5}$ Wolfson Institute of Preventive Medicine, Queen Mary University of London, London, UK
}

Submitted 30 August 2017: Final revision received 27 November 2017: Accepted 6 December 2017; First published online 7 February 2018

\begin{abstract}
Objective: To compare the nutritional content, serving size and taxation potential of supermarket beverages from four different Western countries.

Design: Cross-sectional analysis. Multivariate regression analysis and $\chi^{2}$ comparisons were used to detect differences between countries.

Setting: Supermarkets in New Zealand (NZ), Australia, Canada and the UK.

Subjects: Supermarket beverages in the following categories: fruit juices, fruit-based drinks, carbonated soda, waters and sports/energy drinks.

Results: A total of 4157 products were analysed, including 749 from NZ, 1738 from Australia, 740 from Canada and 930 from the UK. NZ had the highest percentage of beverages with sugar added to them ( $52 \%$ ), while the UK had the lowest ( $9 \%$, $P<0.001)$. Differences in energy, carbohydrate and sugar content were observed between countries and within categories, with UK products generally having the lowest energy and sugar content. Up to half of all products across categories/ countries exceeded the US Food and Drug Administration's reference single serving sizes, with fruit juices contributing the greatest number. Between 47 and $83 \%$ of beverages in the different countries were eligible for sugar taxation, the UK having the lowest proportion of products in both the low tax (5-8\% sugar) and high tax (>8\% sugar) categories.

Conclusions: There is substantial difference between countries in the mean energy, serving size and proportion of products eligible for fiscal sugar taxation. Current self-regulatory approaches used in these countries may not be effective to reduce the availability, marketing and consumption of sugar-sweetened beverages and subsequent intake of free sugars.
\end{abstract}

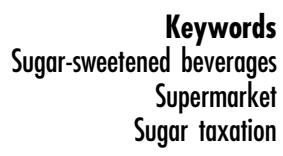

There are significant and growing concerns regarding the adverse health effects of sugar-sweetened beverages (SSB). SSB provide energy but little to no nutrients other than added sugars. Adverse metabolic consequences of SSB consumption have been identified in experimental studies including insulin resistance, inflammation, visceral adiposity and atherogenic dyslipidaemia ${ }^{(1)}$. Furthermore, high consumption of SSB is linked to substantially increased risks of dental decay, obesity, type 2 diabetes and $\mathrm{CVD}^{(1,2)}$. SSB are aggressively marketed and widely consumed across the globe, with a recent Global Burden of Disease modelling study suggesting nearly 185000 deaths per year globally are attributable to SSB consumption ${ }^{(3)}$. Given the accumulated scientific evidence, there is an urgent need for public health interventions to reduce consumption of SSB around the world ${ }^{(4)}$.

Research supports the strong links between food environments and patterns for SSB purchase and consumption. These environmental influences include beverage availability and display, price and marketing ${ }^{(5,6)}$. Despite strong evidence supporting health risks from SSB consumption, the food and beverage industry continues to dominate the market with an abundance of readily available, low-cost, heavily marketed SSB. The WHO recognises this and proposals such as the European Food and Nutrition Action Plan 2015-2020 (7) and the Global Strategy on Diet, Physical Activity and Health ${ }^{(8)}$ recommend fiscal regulation, alongside working closely with the food and beverage industry to decrease the availability 
and marketing of foods and drinks high in added sugars, such as SSB.

Alignment with WHO recommendations varies across the globe, with countries such as Mexico and Spain adopting a strong regulatory approach through taxation of $\operatorname{SSB}^{(9)}$. Other countries such as New Zealand (NZ), Australia and Canada currently avoid SSB fiscal taxation and instead work with the food and beverage industry to self-regulate the availability and marketing of SSB, although taxation of SSB has been suggested in all three countries in recent years, citing the negative impact that these products have on heath ${ }^{(10-12)}$. Currently, the UK plans to introduce a tiered fiscal beverage sugar tax on SSB in April 2018 that proposes three categories of taxation for drinks containing added sugars, based on the percentage of total sugars in the beverage ${ }^{(13)}$.

Public health groups promote ongoing monitoring of the nutritional composition of foods and beverages ${ }^{(14)}$. Such data are needed to inform policy makers and the food industry of areas in the food supply that could be targeted for improvement, enable comparison with dietary guidelines and facilitate cross-sectional benchmarking between countries. Understanding the nutritional composition of foods and beverages is also needed to inform the design of policies such as reformulation and taxation, by identifying the types and numbers of products that will be affected. Finally, if assessed longitudinally, availability of nutrition composition data will also allow objective evaluation of the effectiveness of policies aimed at improving the nutritional composition of the food supply within countries $^{(14)}$. In addition to monitoring the nutritional composition, there are growing interest and calls for more regulations related to the package sizes and manufacturer's recommended serving sizes of foods and drinks $^{(15)}$. Container sizes frequently exceed the reference amounts for beverages as specified by the US Food and Drug Administration (FDA) ${ }^{(16)}$. In particular, carbonated sodas are frequently sold in large product sizes (1-2 litres) and are lower priced compared with other beverages categories. These larger product sizes distort consumer perception of what a 'normal' serving size should be and encourage higher consumption ${ }^{(17)}$.

Relatively few studies have assessed the energy and sugar composition of different categories of SSB products within countries ${ }^{(18-20)}$. The present paper is the first to evaluate differences in the nutritional composition and declared serving size of SSB between countries. To address these gaps in knowledge, the paper aimed to assess the energy and sugar content as well as the package and declared serving sizes of common SSB categories based on data collected from four countries: Australia, Canada, NZ and the UK. These countries were chosen due to availability of data, the rise in obesity in their populations and to meet the strong and growing interest in each country to implement policies targeting SSB consumption, such as reformulation and taxation ${ }^{(21-23)}$.

\section{Methods}

Nutritional composition data were collected from labels of non-alcoholic beverages from supermarkets in NZ, Australia, Canada and the UK between January 2015 and September 2016. The supermarkets chosen for data collection represented the major supermarket retailers in each country and nutrient data were collected from all packaged beverages within the chosen supermarket stores $^{(24)}$. In NZ, data were collected from four large supermarkets in Auckland (representing 92\% grocery market share) using a smartphone app as part of a larger ongoing study ${ }^{(25)}$. Nutrition information was recorded into an online database (NutriWeb ${ }^{\circledR}$ ) before extracting for analysis. Australian data were collected from four retail supermarket stores in Sydney, using the FoodSwitch Data Collector App, before entering into The George Institute's branded food composition database ${ }^{(26)}$. These retail supermarkets represent $88 \%$ of grocery market share in Australia. Canadian data were collected in the Greater Toronto area of Ontario from the three largest supermarkets in Canada, representing $68 \%$ grocery market share. The data were collected using the Food Label Information Program (FLIP) smartphone app and stored in the online FLIP database ${ }^{(27)}$. Data from the UK were collected from nine different supermarket chains in the Greater London and surrounding areas, to cover $87 \%$ of market share. These data were also collected using the FoodSwitch Data Collector App and stored in the UK FoodSwitch online database. Additional beverage products were also collected from all four countries using online shopping stores. These included Countdown (NZ), Coles (Australia), Tesco's and Sainsburys (UK), and Zehr's and Loblaws (Canada). Nutritional content was taken directly from the supermarket websites. Approximately $10 \%$ of the online products were checked against the nutritional information available on the manufacturer websites, with no errors detected.

The present study included all beverages categories that contained SSB and that were available in all four countries for cross-comparison. This included fruit and vegetable juices (in which the product contained $100 \%$ juice or juice was the majority (highest proportion) ingredient), fruitbased drinks (in which juice was present but water was the majority ingredient), carbonated soda drinks, water drinks (including carbonated and flavoured waters as well as coconut water), and sports and energy drinks. Due to a lack of data from one or more of the four different countries, tea- and coffee-based beverages were excluded, as were milk/protein-based beverages. All alcoholic beverages, dry concentrate beverage mixes and concentrated cordials were also excluded; products were included in the analysis only if the product and nutritional information represented a ready-to-drink beverage.

For each product, the following data were recorded from the product nutrition labels: brand name, product 
name, energy $(\mathrm{kJ})$, protein, fat, carbohydrate and sugar content $(\mathrm{g} / 100 \mathrm{ml})$, ingredients list, manufacturer-declared serving size and number of servings per pack. Where the amount of sugar/carbohydrate was recorded as 'less than one gram' it was entered into the spreadsheet as $0.5 \mathrm{~g}$.

All data were transferred to a Microsoft ${ }^{\circledR}$ Excel 2010 spreadsheet for cleaning. Identical products recorded in different stores and different pack sizes of the same product (within a country) were considered duplicates and removed from the data set. Product data were also removed where nutritional information was not recorded (this was less than $1 \%$ of all products). Where possible, any missing data (ingredients or nutritional information) were later added to the spreadsheet by checking the product labels in question, either by viewing the product in the supermarket or on the manufacturer's website. Most serving sizes in Canada were reported in millilitres but a small number of products were given in fluid ounces (these were products of the USA). All imperial measures were converted to millilitres for analysis (1 US fluid ounce $=29.56 \mathrm{ml}$ ).

\section{Data analyses}

\section{Volumetric nutritional content}

Descriptive statistics report the mean total energy $(\mathrm{kJ})$, total sugar and carbohydrate content $(\mathrm{g} / 100 \mathrm{ml})$ of each beverage category, compared by country. Descriptive statistics also report the number and percentage of products that contain added sugar, including all those in which sugar, cane sugar, honey, glucose-fructose syrup, glucose, sucrose, fructose and high-fructose corn syrup were reported on the label ingredients list $(\geq 0 \cdot 1 \mathrm{~g} / \mathrm{l})$. Multivariate regression analysis tested for total sugar $(\mathrm{g} / 100 \mathrm{ml})$ using country as the predictor and the sugar content of each of the five beverage categories as the outcome. Post hoc tests with simple between-country contrasts identified the influential countries that contributed to any significant differences.

\section{Serving size}

Analyses also determined the proportion of products in each country that exceeded the reference serving size for each beverage category ${ }^{(16,28)}$. A reference amount of a beverage refers to that usually consumed by a person per consumption occasion ${ }^{(16)}$. To calculate this, the serving size as declared on the pack by the manufacturer was used for comparison. Due to a lack of equivalent guidelines in all the countries in question, the FDA reference maximum single serving sizes of $250 \mathrm{ml}$ for fruit juice and fruit-based drinks, $375 \mathrm{ml}$ for carbonated and non-carbonated (nonfruit) beverages, and $600 \mathrm{ml}$ for water and sports drinks were used to calculate the number of products in each country/category that exceeded the reference serving size $^{(16,28)}$. The maximum value for each range was used as the reference measure to determine the number of products that exceeded this single serving amount. Pearson's $\chi^{2}$ tests tested for differences in the proportions of beverages in each country that exceeded these FDA reference recommendations.

\section{Nutritional content per serving}

To further evaluate how consumption of SSB may relate to current dietary guidelines, the proportions of single serving products whose total free sugar content exceeded the WHO recommendations of $<5 \%$ and $<10 \%$ of total daily energy intake were calculated ${ }^{(29)}$. This analysis was carried out using all beverages in which the product container was an actual single serving size $(\leq 600 \mathrm{ml})^{(16)}$, rather than using the manufacturer-declared serving size of all products. To calculate the number of products that exceeded the WHO recommendations, the mean free sugar content $(\mathrm{g})$ of each single serving product was determined (using the total product size and data from the nutritional information panel). Reference data from the UK Scientific Advisory Committee on Nutrition report that 5\% of total energy as free sugars is equivalent to $19-25 \mathrm{~g}$ for children aged $4-10$ years and $30 \mathrm{~g}$ for children aged $\geq 11$ years and adults ${ }^{(30)}$. Based on an average 2014 UK total energy intake of $6400 \mathrm{~kJ}$ (children) and $9600 \mathrm{~kJ}$ (adults), a $5 \% / 10 \%$ level of free sugars was calculated to be $20 \mathrm{~g} / 40 \mathrm{~g}$ for children and $30 \mathrm{~g} / 60 \mathrm{~g}$ for adults, respectively ${ }^{(30)}$. Free sugar was defined as all monosaccharides (e.g. glucose and fructose) and disaccharides (e.g. sucrose) added to the beverage by the manufacturer as well as all naturally occurring sugars present in honey, syrups, fruit juices and juice concentrates ${ }^{(13)}$.

\section{Taxation}

Data were analysed to determine the number of products that may potentially be affected by a sugar tax using the proposed 2018 UK three-tiered soft drinks industry levy (SDIL) $^{(30)}$. Taxation categories were $<5 \mathrm{~g} /$ sugar $/ 100 \mathrm{ml}$ (no tax), 5-8 sugar/ $100 \mathrm{ml}$ (18\% tax per litre) and $>8 \mathrm{~g}$ sugar/ $100 \mathrm{ml}$ (24\% tax per litre). Pure fruit juices (100\%) and milk-based drinks are excluded from the proposed tax, hence the fruit juice category was excluded from this analysis. Pearson's $\chi^{2}$ tests were used to determine if there were statistical differences between countries. Descriptive analyses report the number of products in each beverage category in each taxation bracket.

\section{Statistical analysis}

All data analyses were performed per $100 \mathrm{ml}$ of product unless described otherwise. Data were organized and processed in Microsoft ${ }^{\circledR}$ Excel 2010. Statistical analyses were performed using the statistical software package IBM SPSS Statistics version 24. A Bonferroni adjustment was applied for multivariate testing and significance was accepted at $P \leq 0.0125$ (for comparison between the four countries). 


\section{Results}

After data cleaning, a total of 4157 products were used for analysis including 749 from NZ, 1738 from Australia, 740 from Canada and 930 from the UK.

\section{Volumetric nutritional content}

Overall, NZ had the largest proportion of supermarket beverages that contained added sugar (52.3\%). This was significantly higher than Australia (42.2\%), Canada (42.8 \%) and the UK $(9.0 \% ; P \leq 0.001)$. Table 1 presents the mean total energy $(\mathrm{kJ})$, total sugar and carbohydrate content $(\mathrm{g} / 100 \mathrm{ml})$ of each beverage category by country.

There were significant differences between countries for the sugar content of beverages. These differences applied across carbonated sodas $\left(F_{(\mathrm{df} 3)}=19.9, P<0.001\right)$, fruit-based drinks $\left(F_{(\mathrm{df} 3)}=11.5, \quad P<0.001\right)$, water $\left(F_{(\mathrm{df} 3)}=4.0, \quad P=0.009\right) \quad$ and sports/energy drinks $\left(F_{(\mathrm{df} 3)}=3.9, P=0.01\right)$. The UK had a significantly lower sugar content than other countries in the carbonated soda, fruit drink and sports/energy beverage categories. Canada had a lower sugar content than Australia and NZ in the carbonated soda and water categories.

For carbonated soda sugar content, significant betweencountry differences were found for Australia and NZ $v$. UK (both $P \leq 0.001$ ) and Australia and NZ $v$. Canada $(P=0.0125$ and 0.003 respectively). Canada was not significantly different from the UK $(P=0 \cdot 48)$. Table 1 highlights the significantly lower mean sugar content of carbonated sodas for the UK.

For fruit drinks, the lower mean sugar content for the UK was significantly different from Australia, NZ and Canada $(P<0 \cdot 001)$, with no other significant differences between the latter three countries (Table 1). For the water category, significant differences existed between NZ and Canada $(P=0 \cdot 001)$ for mean sugar content. Comparisons between Australia and Canada $(P=0.028)$ and UK and Canada $(P=0.06)$ did not reach the required statistical significance.

In the sports/energy drink category, the UK $(P=0 \cdot 01)$ and Australia $(P=0.001)$ were significantly different from NZ and Canada, with a lower mean sugar content. Fruit juices were the only beverage category where there were no significant differences in mean sugar content (includes natural sugars) between the four countries $\left(F_{(\mathrm{df} 3)}=0.568, P=0.637\right.$; Table 1$)$.

\section{Serving size}

Overall, Australia had the largest percentage of total products in which the manufacturer's declared serving size exceeded the FDA reference maximum serving size for the product category; $36 \%$ of Australian products exceeded this,

Table 1 Nutritional composition analysis of beverages from supermarkets in New Zealand (NZ; $n$ 749), Australia ( $n$ 1738), Canada ( $n$ 740) and the UK ( $n$ 930); data collected from labels in January 2015-September 2016

\begin{tabular}{|c|c|c|c|c|c|c|c|c|c|c|c|c|c|}
\hline & \multicolumn{3}{|c|}{ Number of products } & \multicolumn{4}{|c|}{ Total energy $(\mathrm{kJ} / 100 \mathrm{ml})$} & \multicolumn{4}{|c|}{ Sugar content $(\mathrm{g} / 100 \mathrm{ml})$} & & \\
\hline & \multirow{2}{*}{$\frac{\text { Total }}{n}$} & \multicolumn{2}{|c|}{ Sugar added* } & \multicolumn{2}{|c|}{ All products } & \multicolumn{2}{|c|}{$\begin{array}{l}\text { Sugar-containing } \\
\text { products } \dagger\end{array}$} & \multicolumn{2}{|c|}{ All products } & \multicolumn{2}{|c|}{$\begin{array}{l}\text { Sugar-containing } \\
\text { products } \dagger\end{array}$} & \multicolumn{2}{|c|}{$\begin{array}{l}\text { regression analysis } \\
\text { sugar content }\end{array}$} \\
\hline & & $n$ & $\%$ & Mean & SD & Mean & SD & Mean & SD & Mean & SD & $F$ & $P$ \\
\hline \multicolumn{4}{|c|}{ Carbonated soda } & & & & & & & & & $19 \cdot 9$ & $<0.001$ \\
\hline $\mathrm{NZ}$ & 231 & 189 & $81 \cdot 8$ & $150 \cdot 6$ & 72.8 & $167 \cdot 2$ & 33.5 & $8 \cdot 4$ & $4 \cdot 3$ & 9.5 & $2 \cdot 1$ & & \\
\hline Australia & 312 & 262 & $84 \cdot 0$ & $145 \cdot 4$ & 72.4 & $169 \cdot 2$ & $46 \cdot 7$ & $8 \cdot 3$ & $4 \cdot 1$ & $9 \cdot 7$ & $2 \cdot 1$ & & \\
\hline Canada & 156 & 101 & 64.7 & $122 \cdot 6$ & $89 \cdot 0$ & $171 \cdot 7$ & $48 \cdot 1$ & $7 \cdot 2$ & 5.4 & $10 \cdot 4$ & 3.0 & & \\
\hline UK & 227 & 129 & $56 \cdot 8$ & $87 \cdot 7$ & $79 \cdot 3$ & $124 \cdot 7$ & $68 \cdot 3$ & $4.8 \rrbracket$ & $4 \cdot 8$ & $7 \cdot 1$ & $4 \cdot 2$ & & \\
\hline \multicolumn{4}{|c|}{ Fruit-based drinksł } & & & & & & & & & 11.5 & $<0.001$ \\
\hline $\mathrm{NZ}$ & 115 & 80 & $69 \cdot 6$ & $178 \cdot 4$ & $68 \cdot 1$ & $\mathrm{n} / \mathrm{a}$ & $\mathrm{n} / \mathrm{a}$ & 9.8 & 3.6 & $\mathrm{n} / \mathrm{a}$ & $\mathrm{n} / \mathrm{a}$ & & \\
\hline Australia & 322 & 254 & 78.9 & $152 \cdot 8$ & $63 \cdot 2$ & $\mathrm{n} / \mathrm{a}$ & $\mathrm{n} / \mathrm{a}$ & 8.5 & 3.5 & $\mathrm{n} / \mathrm{a}$ & $\mathrm{n} / \mathrm{a}$ & & \\
\hline Canada & 165 & 126 & 76.4 & $164 \cdot 3$ & 65.9 & $\mathrm{n} / \mathrm{a}$ & $\mathrm{n} / \mathrm{a}$ & 8.9 & 3.8 & $\mathrm{n} / \mathrm{a}$ & $\mathrm{n} / \mathrm{a}$ & & \\
\hline UK & 207 & 144 & 69.6 & $125 \cdot 0$ & 79.5 & $\mathrm{n} / \mathrm{a}$ & $\mathrm{n} / \mathrm{a}$ & 6.69 & 4.5 & $\mathrm{n} / \mathrm{a}$ & $\mathrm{n} / \mathrm{a}$ & & \\
\hline \multicolumn{4}{|l|}{ Fruit juices§ } & & & & & & & & & 3.9 & 0.009 \\
\hline $\mathrm{NZ}$ & 206 & 25 & $12 \cdot 1$ & $194 \cdot 1$ & 51.6 & $\mathrm{n} / \mathrm{a}$ & $\mathrm{n} / \mathrm{a}$ & 9.8 & 2.9 & $\mathrm{n} / \mathrm{a}$ & $\mathrm{n} / \mathrm{a}$ & & \\
\hline Australia & 687 & 42 & $6 \cdot 1$ & $189 \cdot 3$ & 79.8 & $\mathrm{n} / \mathrm{a}$ & $\mathrm{n} / \mathrm{a}$ & 9.5 & 4.5 & $\mathrm{n} / \mathrm{a}$ & $\mathrm{n} / \mathrm{a}$ & & \\
\hline Canada & 204 & 3 & 1.5 & $203 \cdot 4$ & $50 \cdot 1$ & $\mathrm{n} / \mathrm{a}$ & $\mathrm{n} / \mathrm{a}$ & 9.8 & 2.8 & $\mathrm{n} / \mathrm{a}$ & $\mathrm{n} / \mathrm{a}$ & & \\
\hline UK & 291 & 6 & $2 \cdot 0$ & $188 \cdot 2$ & $42 \cdot 8$ & $\mathrm{n} / \mathrm{a}$ & $\mathrm{n} / \mathrm{a}$ & $9 \cdot 3$ & $2 \cdot 3$ & $\mathrm{n} / \mathrm{a}$ & $\mathrm{n} / \mathrm{a}$ & & \\
\hline \multicolumn{4}{|l|}{ Water\| } & & & & & & & & & 0.57 & 0.637 \\
\hline $\mathrm{NZ}$ & 121 & 35 & 28.9 & $49 \cdot 3$ & $59 \cdot 3$ & 94.8 & $52 \cdot 2$ & 2.5 & 3.2 & $4 \cdot 8$ & 3.0 & & \\
\hline Australia & 295 & 72 & 24.4 & 51.0 & 57.4 & 95.9 & $2 \cdot 6$ & $2 \cdot 6$ & 3.1 & $5 \cdot 0$ & $2 \cdot 6$ & & \\
\hline Canada & 138 & 24 & $17 \cdot 4$ & $31 \cdot 3$ & 52.7 & 95.6 & $48 \cdot 2$ & 1.69 & $2 \cdot 7$ & 4.9 & 2.4 & & \\
\hline UK & 109 & 21 & $19 \cdot 3$ & $37 \cdot 3$ & $55 \cdot 2$ & $66 \cdot 4$ & 61.8 & 1.9 & 3.1 & 3.6 & 3.5 & & \\
\hline \multicolumn{4}{|c|}{ Sports and energy drinks } & & & & & & & & & 3.9 & 0.010 \\
\hline NZ & 76 & 63 & 82.9 & $126 \cdot 4$ & $81 \cdot 3$ & $150 \cdot 6$ & $67 \cdot 1$ & $6 \cdot 6$ & 4.5 & $7 \cdot 9$ & 3.7 & & \\
\hline Australia & 122 & 103 & 84.4 & $110 \cdot 3$ & 64.5 & $115 \cdot 4$ & $61 \cdot 7$ & 5.89 & $2 \cdot 8$ & $6 \cdot 1$ & 2.6 & & \\
\hline Canada & 77 & 63 & $81 \cdot 8$ & $123 \cdot 0$ & $81 \cdot 0$ & $142 \cdot 1$ & $71 \cdot 2$ & $6 \cdot 7$ & $4 \cdot 4$ & $7 \cdot 8$ & 3.7 & & \\
\hline UK & 96 & 63 & 65.6 & $111 \cdot 1$ & 98.5 & $147 \cdot 2$ & 67.4 & $5 \cdot 29$ & 4.7 & 7.5 & 3.5 & & \\
\hline
\end{tabular}

*Includes any of the words 'sugar', 'cane sugar', 'honey', 'glucose-fructose syrup', 'glucose', 'sucrose', 'fructose' and 'high-fructose corn syrup' on the label. †Includes any product that contains $\geq 0.001 \mathrm{~g}$ sugar on the nutrition information panel (includes products with natural and added sugars). As all fruit juices and fruit-based drinks contain sugar rather than sugar-containing products being a subset as with other categories, data for juices and juice-based drinks were reported for 'All products' and reported as 'n/a' for sugar-containing products.

flncludes all juice-containing beverages where water is listed as the majority ingredient.

§lncludes all beverages containing $100 \%$ fruit or vegetable juice or where juice was the majority ingredient (and listed first on the ingredient list).

$\|$ Includes carbonated waters, flavoured waters and coconut water drinks.

ๆCountry (countries) identified in post hoc tests as accounting for the significant difference. 
Table 2 Beverage sugar content in a single serving and proportion of products exceeding the US Food and Drug Administration's (FDA) reference serving size, based on information present on the manufacturer-declared product nutritional information panel (NIP), of beverages from supermarkets in New Zealand (NZ; $n 749)$, Australia ( $n$ 1738), Canada ( $n 740)$ and the UK ( $n 930)$; data collected from labels in January 2015-September 2016

\begin{tabular}{|c|c|c|c|c|c|c|c|c|}
\hline & \multicolumn{2}{|c|}{ Number of products } & \multicolumn{2}{|c|}{ NIP serving size $(\mathrm{ml})$} & \multicolumn{2}{|c|}{$\begin{array}{l}\text { Grams of sugar per } \\
\text { NIP single serving }\end{array}$} & \multirow{2}{*}{$\begin{array}{l}\text { Maximum FDA single } \\
\text { serving size (range) }\end{array}$} & \multirow{2}{*}{$\begin{array}{c}\% \text { Products exceeding } \\
\text { the maximum FDA } \\
\text { serving size } \neq\end{array}$} \\
\hline & Total & Containing sugar* & Mean & SD & Mean & SD & & \\
\hline \multicolumn{9}{|c|}{ Carbonated soda } \\
\hline NZ & 231 & 207 & 298.0 & $96 \cdot 5$ & 28.6 & $12 \cdot 1$ & \multirow[t]{4}{*}{$375 \mathrm{ml}(250-375 \mathrm{ml})$} & $7 \cdot 4^{\mathrm{a}}$ \\
\hline Australia & 312 & 268 & 295.9 & $80 \cdot 3$ & $29 \cdot 3$ & $12 \cdot 2$ & & $4 \cdot 7^{b}$ \\
\hline Canada & 156 & 105 & 297.6 & 44.5 & $30 \cdot 2$ & $11 . \overline{6}$ & & $3 \cdot 2^{b}$ \\
\hline UK & 227 & 155 & $262 \cdot 2$ & $43 \cdot 4$ & $19 \cdot 8$ & $12 \cdot 3$ & & $1.8^{\mathrm{C}}$ \\
\hline \multicolumn{9}{|c|}{ Fruit-based drinks§ } \\
\hline $\mathrm{NZ}$ & 115 & 114 & $251 \cdot 4$ & $90 \cdot 0$ & $24 \cdot 0$ & $12 \cdot 2$ & \multirow[t]{4}{*}{$250 \mathrm{ml}(175-250 \mathrm{ml})$} & $11 \cdot 4^{\mathrm{a}}$ \\
\hline Australia & 322 & 312 & $259 \cdot 8$ & 85.8 & $21 \cdot 7$ & $10 \cdot 9$ & & $21 \cdot 8^{\mathrm{b}}$ \\
\hline Canada & 165 & 158 & 252.6 & 44.4 & $22 \cdot 3$ & 9.7 & & $9 \cdot 1^{\mathrm{a}}$ \\
\hline UK & 210 & 167 & $227 \cdot 2$ & $56 \cdot 2$ & $15 \cdot 9$ & $10 \cdot 8$ & & $11 \cdot 5^{\mathrm{a}}$ \\
\hline \multicolumn{9}{|l|}{ Fruit juices $\|$} \\
\hline NZ & 206 & 206 & $246 \cdot 0$ & $48 \cdot 0$ & $24 \cdot 3$ & $9 \cdot 0$ & \multirow[t]{4}{*}{$250 \mathrm{ml}(175-250 \mathrm{ml})$} & $15 \cdot 5^{\mathrm{a}}$ \\
\hline Australia & 687 & 687 & $252 \cdot 4$ & 57.8 & $22 \cdot 6$ & 8.7 & & $55 \cdot 9^{\mathrm{b}}$ \\
\hline Canada & 204 & 204 & $253 \cdot 1$ & 44.8 & $23 \cdot 4$ & 8.0 & & $14 \cdot 7^{\mathrm{a}}$ \\
\hline UK & 291 & 291 & $205 \cdot 3$ & 57.6 & $19 \cdot 3$ & $7 \cdot 4$ & & $7 \cdot 2^{\mathrm{c}}$ \\
\hline \multicolumn{9}{|l|}{ Water } \\
\hline $\mathrm{NZ}$ & 121 & 60 & $349 \cdot 1$ & $169 \cdot 4$ & $14 \cdot 4$ & 7.9 & \multirow[t]{4}{*}{$600 \mathrm{ml}(400-600 \mathrm{ml})$} & $12 \cdot 5^{\mathrm{a}}$ \\
\hline Australia & 295 & 154 & $321 \cdot 7$ & $145 \cdot 1$ & $16 \cdot 2$ & $10 \cdot 8$ & & $3 \cdot 3^{\mathrm{b}}$ \\
\hline Canada & 138 & 42 & $411 \cdot 3$ & $142 \cdot 1$ & $19 \cdot 0$ & $11 \cdot 2$ & & $1.4^{\mathrm{b}}$ \\
\hline UK & 106 & 57 & 266.9 & 64.0 & $13 \cdot 1$ & $11 \cdot \overline{7}$ & & $0.0^{\mathrm{b}}$ \\
\hline \multicolumn{9}{|c|}{ Sports and energy drinks } \\
\hline NZ & 76 & 63 & 597.9 & $247 \cdot 7$ & $43 \cdot 1$ & $19 \cdot 0$ & \multirow[t]{4}{*}{$600 \mathrm{ml}(400-600 \mathrm{ml})$} & $40 \cdot 8^{a}$ \\
\hline Australia & 122 & 103 & 454.4 & $177 \cdot 1$ & $34 \cdot 1$ & 14.0 & & $11.0^{\mathrm{b}}$ \\
\hline Canada & 77 & 66 & $503 \cdot 1$ & $152 \cdot 2$ & $36 \cdot 8$ & $15 \cdot 4$ & & $24 \cdot 0^{C}$ \\
\hline UK & 96 & 66 & 364.9 & $125 \cdot 8$ & $26 \cdot 1$ & $17 \cdot 3$ & & $0.0^{\mathrm{d}}$ \\
\hline
\end{tabular}

a,b,c,d Within each beverage category, percentage values with unlike superscript letters were significantly different $(P \leq 0 \cdot 01)$. *Includes all sugars, both naturally occurring and added.

†Calculated for sugar (either natural or added)-containing products only.

$\ddagger$ Based on the maximum FDA single serving recommendations ${ }^{(16)}$.

SIncludes all juice-containing beverages where water is listed as the majority ingredient.

$\|$ Includes all beverages containing $100 \%$ fruit or vegetable juice or where juice was the majority ingredient.

IIncludes carbonated waters, flavoured waters and coconut water drinks.

compared with $10 \cdot 5,9 \cdot 4$ and $9 \cdot 3 \%$ of NZ, Canada and UK products, respectively (all $P<0 \cdot 001$ ). When comparing beverage categories (irrespective of country), fruit juices had the greatest number of products exceeding the reference serving size $(33.6 \%)$, followed by sports drinks (17.0\%), fruit-based drinks (15.1\%), carbonated soda (4.4\%) and water (4.1\%).

Overall, the mean manufacturer-declared single serving sizes were similar between NZ, Australia and Canada for all fruit juices, fruit-based drinks and carbonated soda, but were consistently lower for the UK (see Table 2). Canada had the highest mean declared single serving size for waters while NZ had the highest mean declared single serving size for sports and energy drinks.

NZ had the highest proportion of carbonated soda products that exceeded the FDA single serving size (significant $v$. the $\mathrm{UK}, P \leq 0 \cdot 01)$; however, Australia had the greatest number of products for fruit juices and juice-based drinks. In all beverage categories, the UK reported the lowest proportion of products that exceeded the FDA recommendations.

\section{Nutritional content per serving}

Similarly, the mean content of sugar (g) per declared serving was also lower in UK products than in those from NZ, Australia and Canada for fruit juices, fruit-based drinks, carbonated soda and sports/energy drinks.
When only those beverages that comprised a single serving pack size $(\leq 600 \mathrm{ml})$ were included for analysis (Table 3), the mean sugar content (natural and/or added) per product was generally comparable between countries for all beverage categories analysed. However, the UK had lower levels of total sugar per product compared with Australia, NZ and Canada for carbonated soda, fruit-based drinks and sports/energy drinks. The greatest number of products that exceeded the $\mathrm{WHO}$ recommendations (products that contain less than $5 \%$ and $10 \%$ of daily energy as free sugars in a single serving as declared on the nutrition information panel) were carbonated sodas, with more than two-thirds of sugarcontaining products in this category in Australia, NZ and Canada exceeding $10 \%$ of an adult's total energy intake as free sugars in one single serving of beverage (see Table 3 ). The UK showed substantially lower proportions of products exceeding the daily free sugar recommendations for several beverage categories, including both at the $\geq 5 \%$ and the $\geq 10 \%$ free sugar level (Table 3).

\section{Potential impact of UK taxation of sugar-sweetened beverages}

The number of products that would potentially be affected by a sugar-levy tax was determined using the proposed UK SDIL ${ }^{(13)}$. The data are shown in Fig. 1. 
Table 3 Sugar content of actual single serving products $(\leq 600 \mathrm{ml})$ and the proportion of single serving products that exceed the WHOrecommended cut-offs of $5 \%$ or $10 \%$ of total daily energy as free sugars* in beverages from supermarkets in New Zealand (NZ; $n 749$ ), Australia ( $n$ 1738), Canada ( $n 740)$ and the UK ( $n$ 930); data collected from labels in January 2015-September 2016

\begin{tabular}{|c|c|c|c|c|c|c|c|c|c|c|}
\hline & \multirow{2}{*}{\multicolumn{2}{|c|}{$\begin{array}{l}\text { Number of single serving } \\
\text { products }(\leq 600 \mathrm{ml})\end{array}$}} & \multirow{2}{*}{\multicolumn{2}{|c|}{$\begin{array}{l}\text { Single serving } \\
\text { size }(\mathrm{ml}) \dagger\end{array}$}} & \multirow{2}{*}{\multicolumn{2}{|c|}{$\begin{array}{l}\text { Grams of sugar per } \\
\text { single servingt, } \ddagger\end{array}$}} & \multicolumn{4}{|c|}{$\begin{array}{l}\% \text { Sugar-containing products exceeding } \\
\text { WHO energy recommendations of free } \\
\text { sugars using serving size } \downarrow, \ddagger, \S\end{array}$} \\
\hline & & & & & & & \multicolumn{2}{|c|}{ Children } & \multicolumn{2}{|c|}{ Adults } \\
\hline & Total $(n)$ & $\begin{array}{l}\text { Containing } \\
\text { sugar }(n)\end{array}$ & Mean & SD & Mean & SD & $\geq 5 \%$ & $\geq 10 \%$ & $\geq 5 \%$ & $\geq 10 \%$ \\
\hline \multicolumn{11}{|c|}{ Carbonated soda } \\
\hline $\mathrm{NZ}$ & 124 & 111 & 358.5 & $16 \cdot 6$ & $35 \cdot 2$ & $10 \cdot 6$ & $86 \cdot 3^{\mathrm{a}}$ & $70.0^{\mathrm{a}}$ & 31.8 & 4.5 \\
\hline Australia & 188 & 165 & 351.9 & $67 \cdot 1$ & $35 \cdot 1$ & 12.5 & $91.5^{a}$ & $71 \cdot 5^{\mathrm{a}}$ & 33.3 & 4.2 \\
\hline Canada & 59 & 42 & 361.4 & 27.5 & 32.4 & 11.1 & $87 \cdot 7^{\mathrm{a}}$ & $67 \cdot 9^{a}$ & 34.6 & $4 \cdot 1$ \\
\hline UK & 68 & 55 & 357.7 & 76.5 & 29.8 & 14.5 & $69 \cdot 0^{\mathrm{b}}$ & $45 \cdot 5^{\mathrm{b}}$ & $12 \cdot 7$ & 1.8 \\
\hline \multicolumn{11}{|c|}{ Fruit-based drinks $\|$} \\
\hline$N Z$ & 43 & 43 & 333.4 & 153.0 & $28 \cdot 7$ & $13 \cdot 7$ & 64.3 & $35 \cdot 7$ & 21.4 & 0.0 \\
\hline Australia & 172 & 172 & $326 \cdot 2$ & 111.5 & $24 \cdot 1$ & 11.3 & 60.5 & $23 \cdot 8$ & $9 \cdot 3$ & 0.0 \\
\hline Canada & 44 & 44 & 330.7 & $122 \cdot 8$ & $25 \cdot 7$ & $9 \cdot 8$ & 67.9 & $31 \cdot 6$ & $17 \cdot 4$ & 1.4 \\
\hline UK & 59 & 55 & $316 \cdot 4$ & 118.8 & $22 \cdot 2$ & 14.8 & 50.9 & 34.5 & 14.5 & 3.6 \\
\hline \multicolumn{11}{|l|}{ Fruit juicesף } \\
\hline $\mathrm{NZ}$ & 72 & 72 & $329 \cdot 1$ & $85 \cdot 7$ & $30 \cdot 2$ & $12 \cdot 2$ & $79 \cdot 2$ & 35.6 & $15 \cdot 3$ & 1.4 \\
\hline Australia & 284 & 284 & $328 \cdot 2$ & 104.4 & $31 \cdot 2$ & $18 \cdot 3$ & $80 \cdot 6$ & $40 \cdot 8$ & $18 \cdot 3$ & $3 \cdot 2$ \\
\hline Canada & 65 & 51 & 321 & $99 \cdot 7$ & $30 \cdot 4$ & $15 \cdot 2$ & $77 \cdot 7$ & $38 \cdot 1$ & $17 \cdot 1$ & 3.5 \\
\hline UK & 104 & 104 & 320.9 & $106 \cdot 4$ & $29 \cdot 0$ & 14.3 & 73.1 & 37.5 & $19 \cdot 2$ & $5 \cdot 8$ \\
\hline \multicolumn{11}{|l|}{ Waters ${ }^{* *}$} \\
\hline $\mathrm{NZ}$ & 65 & 43 & 371.3 & $92 \cdot 9$ & $18 \cdot 8$ & $15 \cdot 3$ & $32 \cdot 6$ & 1.6 & $7 \cdot 0$ & $2 \cdot 3$ \\
\hline Australia & 98 & 55 & 433.5 & $133 \cdot 6$ & $20 \cdot 0$ & $10 \cdot 2$ & $38 \cdot 2$ & 14.5 & $1 \cdot 8$ & 0.0 \\
\hline Canada & 58 & 47 & 412.5 & $120 \cdot 5$ & $19 \cdot 7$ & $10 \cdot 6$ & 41.4 & 16.5 & $3 \cdot 6$ & 1.7 \\
\hline UK & 35 & 25 & 396.4 & 111.3 & 21.5 & $12 \cdot 4$ & $52 \cdot 0$ & $20 \cdot 0$ & 8.0 & 0.0 \\
\hline \multicolumn{11}{|c|}{ Sports and energy drinks } \\
\hline NZ & 45 & 36 & 420.9 & $128 \cdot 2$ & $41 \cdot 2$ & $17 \cdot 3$ & 83.3 & $69 \cdot 4$ & 44.4 & $11 \cdot 1$ \\
\hline Australia & 47 & 31 & $376 \cdot 3$ & 113.9 & 39.8 & $17 \cdot 7$ & $90 \cdot 3$ & $67 \cdot 7$ & $51 \cdot 6$ & $3 \cdot 2$ \\
\hline Canada & 41 & 31 & 384.6 & $111 \cdot 1$ & $39 \cdot 1$ & 16.9 & $87 \cdot 2$ & $59 \cdot 8$ & $49 \cdot 8$ & $6 \cdot 6$ \\
\hline UK & 86 & 62 & 398.0 & $123 \cdot 4$ & $27 \cdot 4$ & $19 \cdot 2$ & $62 \cdot 9$ & $29 \cdot 0$ & $22 \cdot 6$ & 4.8 \\
\hline
\end{tabular}

${ }^{\mathrm{a}, \mathrm{b}}$ Within each beverage category for children, percentage values with unlike superscript letters were significantly different $(P \leq 0.01)$.

*Based on WHO sugar intake guidelines ${ }^{(29)}$.

†Product size irrespective of manufacturer-declared serving size information on the nutrition information panel.

¥Calculated for sugar (either natural or added)-containing products only.

$\S 5 \%$ and $10 \%$ daily energy as free sugars is equivalent to $\geq 20 \mathrm{~g} / 40 \mathrm{~g}$ for children and $\geq 30 \mathrm{~g} / 60 \mathrm{~g}$ for adults ${ }^{(30)}$. Free sugars defined as all monosaccharides (e.g. glucose and fructose) and disaccharides (e.g. sucrose) added to the beverage by the manufacturer as well as all naturally occurring sugars present in honey, syrups, fruit juices and juice concentrates ${ }^{(30)}$.

$\|$ Includes all juice-containing beverages where water is listed as the majority ingredient.

fIncludes all beverages containing $100 \%$ fruit or vegetable juice or where juice was the majority ingredient.

${ }^{\star \star}$ Includes carbonated waters, flavoured waters and coconut water drinks.

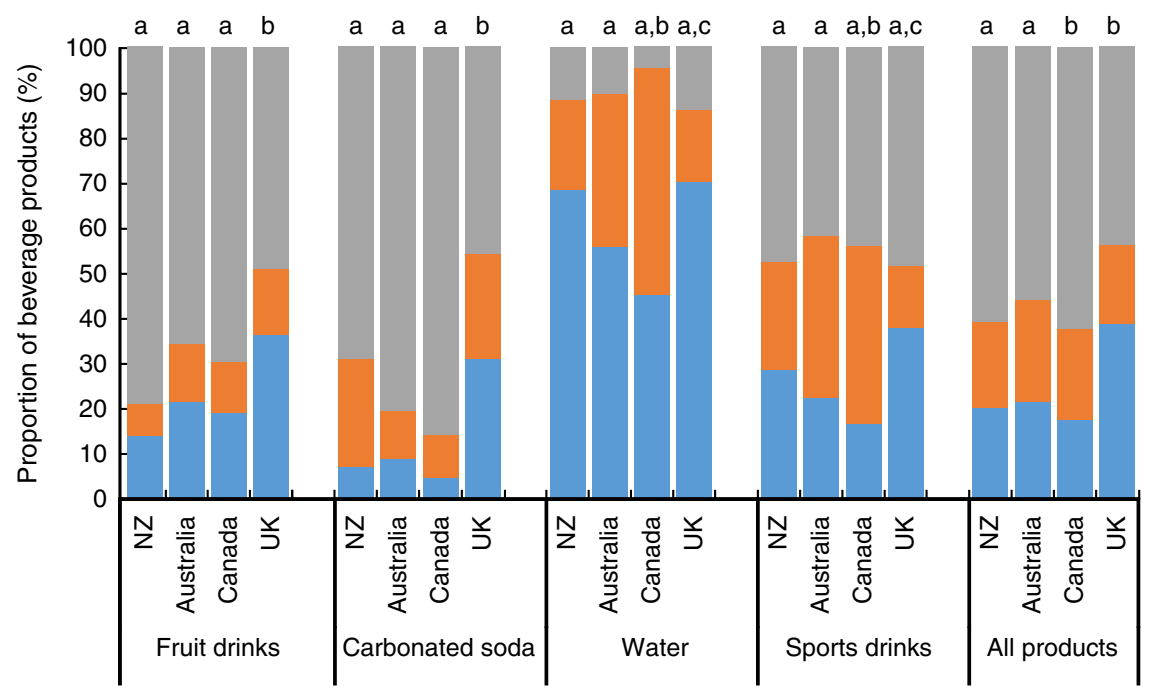

Fig. 1 (colour online) Proportion of beverage products from New Zealand (NZ), Australia, Canada and the UK for which the proposed UK three-tiered sugar-tax levy would apply. The UK sugar-tax levy proposes three categories:,$<5 \mathrm{~g} \mathrm{sugar} / 100 \mathrm{ml}$ (no

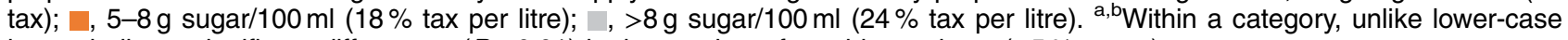
letters indicate significant differences $(P \leq 0.01)$ in the number of taxable products $(\geq 5 \%$ sugar) 
Overall, all four countries had a majority of beverages in all categories that would potentially be subject to taxation using the proposed levy system. Canada had the highest total proportion of products that contained $\geq 5 \%$ sugar and therefore would be eligible for taxation ( $82.5 \%)$, this being statistically higher than Australia $\left(76 \cdot 1 \% ; \chi_{(1, n 1204)}^{2}=6 \cdot 1\right.$, $P=0.01)$ and the UK $\left(61.2 \% ; \chi_{(1, n 1315)}^{2}=46 \cdot 6, P<0.0001\right)$, but not NZ (79.7\%). Canada, Australia and NZ all had comparable proportions of products that would fall into the highest tax bracket of $>8 \%$ sugar $(62 \cdot 3,57 \cdot 3$ and $60.8 \%$, respectively), all three being statistically higher than the UK (43.8\%; all $P<0.0001)$.

Across beverage categories, carbonated soda had the greatest proportion of products that would be taxable overall $(86 \cdot 1 v \cdot 76 \cdot 3,74 \cdot 2$ and $40 \cdot 6 \%$ for fruit-based drinks, sports/energy drinks and waters, respectively). Similarly, carbonated soda had the most products containing $>8 \%$ sugar (70.7 v. 64.0, 45.0 and $10.5 \%$, respectively). As expected, the waters category had the lowest proportion of taxable products, this being due to the lower mean total sugar content compared with other beverage categories (refer to Table 1).

When looking within specific beverage categories, differences were observed for the number of taxable products. Within the fruit-based drinks and the carbonated soda categories, NZ, Australia and Canada all contained proportionally more taxable products than the UK (see Fig. 1). Canada also had the highest level of potentially taxable products in the water and sports/energy drink categories.

\section{Discussion}

Across the four countries, SSB dominate the non-alcoholic beverage market, with Australia having the highest overall percentage of products with added sugar in three of the five beverage categories (fruit-based drinks, carbonated sodas and sports/energy drinks) and NZ having the highest proportion overall. Out of the sugar-containing products, the UK had notably fewer products containing added sugar across four of the five beverage categories, and mean added sugar content was significantly lower for sugar-sweetened carbonated sodas compared with NZ, Australia and Canada $(7 \cdot 1$ v. 9.8, $9 \cdot 8$ and $10 \cdot 5 \mathrm{~g} / 100 \mathrm{ml}$, respectively).

Previous studies investigating the percentage of nonalcoholic beverages containing added sugar sold in NZ supermarkets have reported similar findings to the current study. One study on the availability, serving size and sugar content of non-alcoholic beverages found that $83 \%$ of beverages in 2012 contained added sugar or were naturally sweetened ${ }^{(31)}$. A further study carried out in NZ in 2016 found that $90 \%$ of carbonated beverages, $88 \%$ of cordials and $70 \%$ of fruit drinks contained added sugar ${ }^{(19)}$. Furthermore, in that study, carbonated beverages and fruit juices derived $>85 \%$ of their total energy content from sugar $^{(19)}$.

There appear to be few data on the nutritional content of SSB in Canada, although it has been reported that one in five calories in the Canadian diet comes from sugar, with 35 and $44 \%$ of the daily sugar intake coming from beverages in adults and children, respectively ${ }^{(32)}$. In addition, one study has reported that the median sugar content of beverages in Canada is $9.2 \mathrm{~g} / 100 \mathrm{ml}$ with $72 \%$ of all non-alcoholic beverages having sugar added ${ }^{(27)}$, although there was no breakdown of the sugar content of different beverage categories.

A prior survey of 2014 UK data of carbonated SSB available in nine major UK supermarkets found a higher average free sugar content $(9 \cdot 12 \pm 3 \cdot 2 \mathrm{~g} / 100 \mathrm{ml})^{(13)}$. This higher percentage compared with the current study may be due to the greater number of supermarkets sampled and a different product range, although it is also possible that the free sugar content has been lowered in UK beverages in response to the proposed 2018 SDIL tax levy. In addition, the mean serving size of UK beverages was smaller than those for Canada, Australia and NZ. This may be partly due to a change in guidance in the UK for serving size of fruit juice (now $150 \mathrm{ml}$ ), as well as a change to recommendations for free sugars consumption in line with the WHO recommendations that sugar intake should be less than $10 \%$, and ideally less than $5 \%$, of the total daily energy intake ${ }^{(29)}$. Since carbonated sodas were identified as the main contributor to free sugar intakes in the UK population $^{(33)}$ and public health campaigners have worked to draw attention to the need for reductions in this area, this may explain why manufacturers have worked to reduce the amount of free sugars in their products, as well as offering more low/zero-calorie no-added-sugar alternatives, and changes to recommended serving sizes on packages.

Multiple studies support strong associations between availability, purchasing and consumption of $\mathrm{SSB}^{(33,34)}$. A wastage of $30-40 \%$ is predicted to occur between availability and consumption, but generally the higher the availability of SSB, the higher the population consumption $^{(35)}$. Using annual food balance information collected by the FAO, Singh et al. calculated proxy SSB availability data based on total sugar and fruit availability, with known percentages of each that go into production of SSB and fruit juice, respectively ${ }^{(36)}$. Across 187 countries, NZ had the highest consumption of fruit juices at an average of 0.83 (95\% uncertainty interval $0.44,1.44$ ) servings daily in $2010^{(36)}$. Australia also had a high consumption of fruit juice. Although these consumption patterns date back to 2010, they align with the number of fruit juice products available in the current study, where NZ had two to six times more fruit juice products available than the other countries, and Australia had three to four times more than the UK and Canada, respectively (Table 1). While this does not directly reflect increased risk for 
non-communicable diseases within populations, inevitably these associations suggest higher consumption of SSB, which is one of many factors contributing to obesity and related diseases.

High dietary intakes also relate to the portion sizes consumed; the Australian Adult Nutrition Survey (AANS) indicated that the top $10 \%$ of SSB consumers drink up to 1.5 litres $/ \mathrm{d}^{(17)}$. In the current study up to $56 \%$ of manufacturer-declared single serving sizes exceeded the FDA reference serving size. Furthermore, SSB sold in larger containers (i.e. 500/600 ml bottles) can be consumed in one sitting, even if the packaging recommends two or three servings per pack, and therefore result in an increased intake of added sugar. However, while there appears to be no evidence that SSB serving sizes have decreased in recent years, it has been reported that SSB intake may be declining over time. AANS reported that SSB consumption has reduced from $43 \%$ of the population in 1995 to $34 \%$ of the population in $2011^{(17)}$. Similar data from the UK National Diet and Nutrition Survey ${ }^{(37)}$ and the Canadian Community Health Survey ${ }^{(34)}$ show that SSB consumption has decreased across all age groups since 2008, although all studies report that sugar consumption from beverages is still high and well above WHO recommendations, particularly in youth and adolescents. A recent study published in $2017^{(38)}$ suggests that reductions in package size may also successfully decrease SSB consumption further, although these authors note that the majority of package/portion size initiatives are voluntary and at the discretion of the food industry. Modelling has suggested that a package size cap of $375 \mathrm{ml}$ for SSB would result in a reduction of body weight of $0 \cdot 12 \mathrm{~kg}$, this improving further to a $0.23 \mathrm{~kg}$ reduction if the products were also reformulated to reduce the energy content $^{(38)}$.

Despite the reductions in SSB noted above, it is clear from the findings of the present study that the current nutrient composition of SSB, their high availability and large serving sizes are not conducive to reducing the intake of added sugar in the population. This is particularly applicable in NZ and Australia, which consistently had the highest proportion of SSB for each of the five beverage categories included in the present study. Current WHO guidelines and recommendations for maximum consumption of added sugar are exceeded across all countries and the present study suggests that beverage manufacturers do not adhere to them either, selling beverages in serving sizes that provide more added sugar per serving than $10 \%$ of total energy intake. The present study found that NZ had the highest percentage of fruit juices with sugar added. Consumption of fruit juices does not align with the most recent guidance in the NZ Ministry of Health's food and activity guidelines for both children $^{(39)}$ and adults ${ }^{(40)}$, where fruit juice is no longer recognized as a fruit serving and is advised for nil or occasional consumption only. This suggests that self-regulation by the food and beverage industry is not aligning with the recommended healthy eating guidelines.

Research does show that fiscal regulation can positively affect SSB intake. In Mexico, for example, an excise tax on SSB introduced in 2012 appears to have decreased purchasing of SSB by $5 \%$ in the first-year post tax, and then up a $12 \%$ decrease in the second year ${ }^{(41)}$. Importantly, however, this taxation cost was passed on to the consumer and thus had the greatest effect on low socio-economic groups (who also demonstrated the highest price elasticity of demand) ${ }^{(42)}$. In addition, a review of the feasibility of SSB taxation in Canada suggests that SSB purchasing and consumption would likely decrease as a result of a tax that involves a price increase of $10-20 \%{ }^{(43)}$. In contrast, the UK SDIL tax is targeted at manufacturers with the cost purported to not be passed on to the consumer. Thus, in the UK, the impetus on not on a reduction of SSB sales but on reformulation (lowering of sugar content) to avoid taxation.

When the proposed UK SDIL was applied to all the data in the present study as a formula to derive the percentage of products across each category that would be subject to sugar taxation, carbonated sodas were the category most affected, with $86 \%$ taxable overall, the majority of these in the $>8 \mathrm{~g}$ sugar $/ 100 \mathrm{ml}$ tax bracket. Across all categories (except energy/sports drinks), the UK had a significantly lower percentage of products that would be subject to taxation than the other three countries. It is possible that the impending fiscal taxation on sugar is stimulating the UK beverage industry to reformulate existing product lines to reduce their added sugar content, reduce recommended serving size, and offer more products in the lowsugar/sugar-free categories (that will not be subject to taxation) and fewer products in the $5-8 \mathrm{~g}$ sugar $/ 100 \mathrm{ml}$ and $>8 \mathrm{~g}$ sugar/100 $\mathrm{ml}$ categories that will be subject to taxation. More research is needed on the effects of both impending and implemented fiscal taxation of sugar; however, it may be a useful catalyst to encourage manufacturers to take action.

Various studies have reported that sugar taxation reduces the prevalence of obesity and obesity-related disease $^{(22,44)}$, although the impact of SSB taxation on these outcomes seems less clear and needs further evaluation.

One of the limitations of the current study is that different methods for collection of data were used between countries, which may have influenced the comparability of data. Additionally, data on milk-based beverages were not collected across all countries, so this excluded an entire category of SSB from the analysis. This omission was important to allow for a complete cross-country comparison, but may affect the interpretation of the market for single countries where flavoured milk is a popular choice.

A further limitation is that the data were collected at slightly different times during the year for each country, which may have introduced a seasonal effect on the product range at the time of data collection. The authors 
also note that while all available beverages meeting the study criteria were included in the beverage list for each category/country, this resulted in an uneven number of products across countries, with Australia having far more products available for each category than the other three countries. This may have influenced the findings and conclusions drawn from the data. Lastly, the study looked specifically at nutrition composition data and no purchasing or consumption data were collected. The latter are essential to determine the impacts of taxation and manufacturer reformulation on health outcomes. However, the strength and scientific contribution of our study is that it offers a snapshot comparison of the nutrient content and availability of SSB across four countries with different policies and guidelines around the composition and regulation of SSB. This offers some relevant comparisons about the potential effects of fiscal $v$. self- or informal regulation of the beverage industry with regard to SSB, and identifies further areas where research is needed and why additional policies are required to reduce free sugar intakes in these populations.

\section{Conclusion}

Substantial differences exist across countries, particularly with regard to the free sugar content of carbonated sodas, fruit juices, fruit drinks and energy/sports drinks. The beverage industry in NZ and Australia, in particular, is replete with nutrition-poor, energy-dense beverages that are heavily marketed and readily available. Self-regulation by the food and beverage industry is not working and policies are urgently required that influence the purchasing of SSB (e.g. through marketing, composition, price and availability) as a strategy to address factors that contribute significantly to the current obesity epidemic and high intakes of free sugars in these countries. Implementation of a levy or other regulatory policies, such as the setting of mandatory targets, could be effective in encouraging manufacturers to reduce the sugar content of beverages and thereby reduce consumption of added sugar, helping to combat obesity and improve public health.

\section{Acknowledgements}

Acknowledgments: The authors would like to thank Dr Helen Eyles (Auckland University, NZ) for providing some of the data for analysis. They would also like to thank Dr Mary L'Abbe and Alyssal Schermel of the University of Toronto for the use of the mobile data collection app and access to their FLIP nutrition database. Thanks also go to Jodi Bernstein for her support with manuscript review. Financial support: A student summer scholarship payment was awarded to S.H. to support the data cleaning and analysis. Conflict of interest: None. Authorship: L.C. collected the Canadian data, undertook the statistical analyses and manuscript preparation. S.H. undertook all data entry and cleaning. M.C. was responsible for collation of Australian data. S.A. and K.J. were responsible for collection of UK data. S.A., K.J., G.M. and J.H.Y.W. assisted with manuscript writing and preparation. Ethics of human subject participation: Not applicable.

\section{References}

1. Malik VS, Popkin BM, Bray GA et al. (2010) Sugarsweetened beverages, obesity, type 2 diabetes mellitus, and cardiovascular disease risk. Circulation 121, 1356-1364.

2. Malik VS \& Hu FB (2015) Fructose and cardiometabolic health: what the evidence from sugar-sweetened beverages tells us. J Am Coll Cardiol 66, 1615-1624.

3. Singh GM, Micha R, Khatibzadeh S et al. (2015) Estimated global, regional, and national disease burdens related to sugar-sweetened beverage consumption in 2010. Circulation 132, 639-666.

4. Ravelo JL (2016) WHO says no to sugary drinks at headquarters. http://www.devex.com/news/who-says-no-tosugary-drinks-at-headquarters-88905 (accessed September 2017).

5. Han E \& Powell LM (2013) Consumption patterns of sugarsweetened beverages in the United States. J Acad Nutr Diet $\mathbf{1 1 3}, 43-53$.

6. Gustafson A, Christian JW, Lewis S et al. (2011) Food venue choice, consumer food environment, but not food venue availability within daily travel patterns are associated with dietary intake among adults, Lexington Kentucky. Nutr J 12, 17.

7. World Health Organization (2014) European Food and Nutrition Action Plan 2015-2020. Copenhagen: WHO Regional Office for Europe; available at http://www.euro. who.int/_data/assets/pdf_file/0008/253727/64wd14e_Food NutAP_140426.pdf.

8. World Health Organization (2017) Global Strategy on Diet, Physical Activity and Health. Geneva: WHO; available at http://www.who.int/dietphysicalactivity/en/

9. World Health Organization (2016) Fiscal Policies for Diet and the Prevention of Noncommunicable Diseases: Technical Meeting Report, 5-6 May 2015, Geneva, Switzerland. Geneva: WHO; available at http://www.who.int/iris/handle/ $10665 / 250131$

10. Veerman JL, Sacks G, Antonopoulos N et al. (2016) The impact of a tax on sugar-sweetened beverages on health and health care costs: a modelling study. PLoS One 11, e0151460

11. Beaglehole R (2014) Sugar sweetened beverages, obesity, diabetes and oral health: a preventable crisis. Pac Health Dialog 20, 39-42.

12. Dietitians of Canada (2016) Taxation and Sugar-Sweetened Beverages: Position of Dietitians of Canada. http://www. dietitians.ca/Downloads/Public/DC-Position-SSBs-and-taxation. aspx (accessed May 2017).

13. Hashem KM, He FJ, Jenner KH et al. (2016) Cross-sectional survey of the amount of free sugars and calories in carbonated sugar-sweetened beverages on sale in the UK. BMJ Open 6, e010874.

14. Neal B, Sacks G, Swinburn B et al. (2013) Monitoring the levels of important nutrients in the food supply. Obes Rev 14, Suppl. 1, 49-58.

15. Wang YC \& Vine SM (2013) Caloric effect of a 16ounce $(473-\mathrm{mL})$ portion-size cap on sugar-sweetened beverages served in restaurants. Am J Clin Nutr 98, 430-435. 
16. US Food and Drug Administration (2016) Code of Federal Regulations Title 21. Reference Amounts Customarily Consumed (RACCs). http://www.fda.gov/downloads/food/ guidanceregulation/guidancedocumentsregulatoryinformation/ labelingnutrition/ucm513820.pdf (accessed June 2017).

17. Australian Bureau of Statistics (2014) Australian Health Survey: Nutrition First Results - Food and Nutrients, 2011-12. Canberra: ABS, Commonwealth of Australia.

18. Ventura EE, Davis JN \& Goran MI (2011) Sugar content of popular sweetened beverages based on objective laboratory analysis: focus on fructose content. Obesity (Silver Spring) 19, 868-874.

19. Chepulis L, Mearns GJ \& Skinner K (2017) Sugar content of supermarket beverages commonly consumed by children in New Zealand. Aust N Z J Public Health 41, 321-322.

20. Walker KZ, Woods JL, Rickard CA et al. (2008) Product variety in Australian snacks and drinks: how can the consumer make a healthy choice? Public Health Nutr 11, 1046-1053.

21. New Zealand Beverage Guidance Panel (2014) Policy Brief: options to reduce sugar sweetened beverage (SSB) consumption in New Zealand. Pac Health Dialog 20, 98-102.

22. Brownell KD, Farley T, Willett WC et al. (2009) The public health and economic benefits of taxing sugar-sweetened beverages. N Engl J Med 361, 1599-1605.

23. Briggs AD, Mytton OT, Kehlbacher A et al. (2013) Overall and income specific effect on prevalence of overweight and obesity of $20 \%$ sugar sweetened drink tax in UK: econometric and comparative risk assessment modelling study. BMJ 347, f6189.

24. Euromonitor plc (2014) Passport Global Market Information Database. London: Euromonitor.

25. Eyles H, Neal B, Jiang Y et al. (2016) Estimating population food and nutrient exposure: a comparison of store survey data with household panel food purchases. Br J Nutr 115, $1835-1842$.

26. Trevena H, Neal B, Dunford E et al. (2014) An evaluation of the effects of the Australian Food and Health Dialogue targets on the sodium content of bread, breakfast cereals and processed meats. Nutrients $\mathbf{6}, 3802-3817$.

27. Bernstein JT, Schermel A, Mills CM et al. (2016) Total and free sugar content of Canadian prepackaged foods and beverages. Nutrients $\mathbf{8}$, E582.

28. Canadian Food Inspection Agency (2016) Food Labelling: Reference Amount and Serving Sizes. http://www.inspection. gc.ca/food/labelling/food-labelling-for-industry/nutritionlabelling/information-within-the-nutrition-facts-table/eng/138 9198568400/1389198597278? chap $=5$ (accessed August 2017).

29. World Health Organization (2015) Guideline: Sugars Intake for Adults and Children. Geneva: WHO; available at http:// apps.who.int/iris/bitstream/10665/149782/1/9789241549028_ eng.pdf

30. Barber S \& Baker C (2016) Briefing Paper Number 7876: The Soft Drinks Industry Levy. http://www.cliftondavies. com/wp-content/uploads/2017/01/HoC-Soft-Drinks-IndustryLevy-Briefing-Paper.pdf (accessed August 2017).

31. Ni Mhurchu C \& Eyles H (2014) Sweetened and unsweetened non-alcoholic beverages in New Zealand: assessment of relative availability, price, serve size, and sugar content. Pac Health Dialog 20, 51-58.

32. Langlois K \& Garriguet D (2011) Sugar consumption among Canadians of all ages. Health Rep 22, issue 3, 23-27.

33. Merchant AT, Tripathi A \& Pervaiz F (2010) Available energy from soft drinks: more than the sum of its parts. Public Health Nutr 13, 1997-1999.

34. Brisbois T, Marsden S, Anderson G et al. (2014) Estimated intakes and sources of total and added sugars in the Canadian diet. Nutrients 6, 1899-1912.

35. Popkin BM \& Hawkes C (2016) Sweetening of the global diet, particularly beverages: patterns, trends, and policy responses. Lancet Diabetes Endocrinol 4, 174-186.

36. Singh GM, Micha R, Khatibzadeh S et al. (2015) Global, regional, and national consumption of sugar-sweetened beverages, fruit juices, and milk: a systematic assessment of beverage intake in 187 countries. PLOS One 10, e0124845.

37. Public Health England (2014) NDNS: Results from Years 1 to 4 (Combined). Results of the National Diet and Nutrition Survey (NDNS) Rolling Programme for 2008 and 2009 to 2011 and 2012. London: Public Health England; available at https://www.gov.uk/government/collections/nationaldiet-and-nutrition-survey

38. Crino M, Herrera AMM, Ananthapavan J et al. (2017) Modelled cost-effectiveness of a package size cap and a kilojoule reduction intervention to reduce energy intake from sugar-sweetened beverages in Australia. Nutrients $\mathbf{9}$, E983.

39. New Zealand Ministry of Health (2012) Food and Nutrition Guidelines for Healthy Children and Young People (Aged 2-18 years): A Background Paper. http://www.health.govt. $\mathrm{nz} /$ system/files/documents/publications/food-nutritionguidelines-healthy-children-young-people-backgroundpaper-feb15-v2.pdf (accessed February 2017).

40. New Zealand Ministry of Health (2015) Eating and Activity Guidelines for New Zealand Adults. http://www.health. govt.nz/system/files/documents/publications/eating-activityguidelines-for-new-zealand-adults-oct15_0.pdf (accessed February 2017).

41. Colchero MA, Popkin BM \& Rivera JA (2016) Beverage purchases from stores in Mexico under the excise tax on sugar sweetened beverages: observational study. BMJ 352, h6704.

42. Colchero MA, Salgado JC, Unar-Munguia M et al. (2015) Price elasticity of the demand for sugar sweetened beverages and soft drinks in Mexico. Econ Hum Biol 19, 129-137.

43. Le Bodo Y, Paquette MC \& De Wals P (2016) Feasibility of sugar-sweetened beverage taxation in Canada. In Taxing Soda for Public Health: A Canadian Perspective, pp. 163-192. Switzerland: Springer International Publishing AG.

44. Hu FB (2013) Resolved: there is sufficient scientific evidence that decreasing sugar-sweetened beverage consumption will reduce the prevalence of obesity and obesity-related diseases. Obes Rev 14, 606-619. 